\title{
Datenschutz beachten!
}

\section{Ärzte dürfen auf Facebook posten}

\section{Die Internetkompetenz des}

Praxisteams ist laut Bayerischer Landesärztekammer eine Schlüsselqualifikation im Praxisalltag. Für die Kommunikation zwischen Patient und Praxis brauchen Ärzte allerdings vor allem juristisches Wissen.

Die Online-Kommunikation zwischen Arzt und Patient ist nach Angaben der Bayerischen Landesärztekammer „kein grundsätzliches Tabu“. Allerdings müssten dabei einige Regeln beachtet werden, erläutert Kammerpräsident Dr. Max Kaplan. Wer als Arzt einen Facebook-Account hat, müsse ganz genau darauf achten, dass keine Patientendaten aus dem elektronischen Adressbuch oder aus dem E-MailPostfach an das soziale Netzwerk übermittelt werden, wenn sich auf dem Computer oder dem Smartphone neben privaten Kontakten auch Patientendaten befinden. Eine Datenweitergabe, etwa via Facebook, könne, wenn ein Arzt die Daten vorsätzlich weitergebe, sogar eine Verletzung der ärztlichen Schweigepflicht darstellen und somit strafbar sein, so Kaplan.

\section{Digitale Praxisunterstützung}

„Dennoch sollten wir Ärztinnen und Ärzte natürlich fit für das Internet sein, E-Mails mit Patienten austauschen, unsere Praxis-Website in regelmäßigen $\mathrm{Ab}$ ständen aktualisieren oder auch einen Praxis-Newsletter verschicken“, ergänzt BLÄK-Vizepräsident Dr. Wolfgang Rechl. Schließlich mache das Internet auch vor den Praxen nicht Halt. Nach Rechls Ansicht benötigen die Ärzte für die webbasierte Kommunikation zwischen Patient und Praxis vor allem technisches und auch juristisches Know-how. Die Internetkompetenz, auch des Praxisteams zur Unterstützung der Praxisleitung, werde daher immer mehr zu einer wichtigen Schlüsselqualifikation im Praxisalltag, betont Rechl.

Bereits heute gebe es zahlreiche hilfreiche Anwendungen, mit denen die ArztPatientenkommunikation besser bewältigt werden könne, so Rechl. Als Beispiele nennt er die Online-Rezeptbestellung und -Terminbuchung, das Führen der elektronischen Krankenakte, die bedarfsgerechte Ressourcenplanung von Personal, die Online-Kommunikation im Ärzte-Netzwerk mit einem papierlosen Austausch von Befunden und Formularen, die digitale Archivierung sowie die Verlaufsdokumentation von DMP.

(Jürgen Stoschek)

\section{Ärzte Zeitung, 23.03.2013}

\section{Klares Privatvergnügen}

\section{Risiko Raucherpause}

Verletzt sich ein Arbeitnehmer auf dem Rückweg von der Raucherpause zum Arbeitsplatz, liegt kein Arbeitsunfall vor.

Das meldet der Deutsche Anwaltverein anlässlich eines aktuellen Urteils des Sozialgerichts Berlin. In der Sache ging es um eine Pflegehelferin, die von einer Raucherpause zu ihrer Arbeit zurückkehrte.

Dabei stieß sie in der Eingangshalle des Seniorenheims mit dem Hausmeister zusammen. Diesem entglitt dabei ein Wassereimer, die Frau rutschte aus und brach sich den rechten Arm.

\section{Rauchen ist Privatvergnügen}

Die Pflegehelferin war der Ansicht, dass es sich um einen Arbeitsunfall handelte. Die Berufsgenossenschaft lehnte die Anerkennung eines Arbeitsunfalls ab. Hiergegen klagte die Frau. Ohne Erfolg: Rauchen sei persönliche Angelegenheit ohne sachlichen Bezug zur Berufstätigkeit, so die Richter.

\section{Kein Anspruch auf Entschädigung und Kostenübernahme}

Deshalb bestehe bei einer Verletzung auch kein Anspruch auf Heilbehandlung, Verletztengeld oder Rente gegenüber der gesetzlichen Unfallversicherung. Es sei die private Entscheidung jedes Einzelnen, ob er zum Rauchen gehe oder nicht.

Das Rauchen sei insbesondere nicht mit der Nahrungsaufnahme vergleichbar. Essen und Trinken seien unter anderem nötig, um die Arbeitskraft aufrechtzuerhalten. Deshalb sei zwar der Weg zur Kantine versichert, nicht aber der Weg von und zur Raucherpause.

(Christoph Winnat)

Az.: S 68 U 577/12; Ärzte Zeitung, 26.02.2013

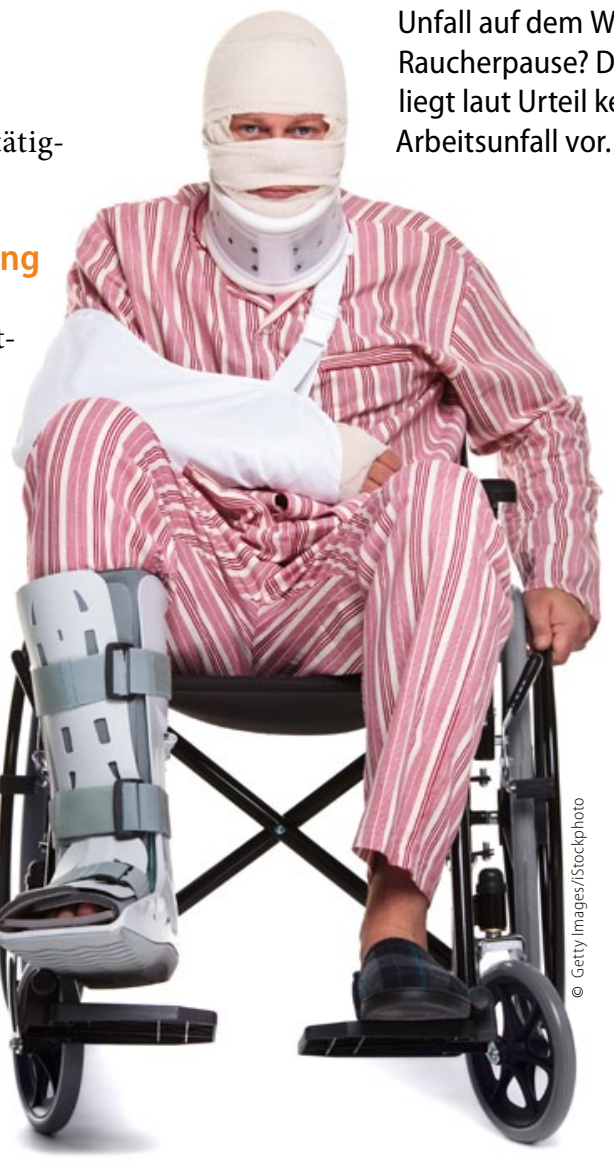

